\title{
Assessment of Knowledge of Tribal Adolescent Girls Regarding Reproductive Health in Meghalaya, India
}

\author{
Shipra Nagar* and Namita Singh
}

College of Home Science, Central Agricultural University, Tura, Meghalaya-794005, India

*Corresponding author

\section{A B S T R A C T}

\begin{tabular}{|l|}
\hline Ke y w o r d s \\
$\begin{array}{l}\text { Reproductive } \\
\text { health, Adolescents, } \\
\text { Menstruation }\end{array}$ \\
\hline Article Info \\
\hline $\begin{array}{l}\text { Accepted: } \\
18 \text { August } 2018 \\
\text { Available Online: } \\
\text { 10 September } 2018\end{array}$ \\
\hline
\end{tabular}

Reproductive health awareness is an important and emerging issue especially among adolescents. The present study aimed to investigate the extent of awareness regarding reproductive health among tribal adolescent girls. A total sample of 100 school going adolescent girls from 13 to 18 years were randomly selected from five villages of South West Garo Hills district of Meghalaya. A pre-tested interview schedule was used to collect information from school going girls. The results revealed that majority of the respondents were in the age range of 15 to 17 years and were studying in $10^{\text {th }}$ standard. The mean age at menarche was found to be 12.67 years. Girls were aware of some of the changes in the body occurring during adolescence but were quite unaware of the development of primary sexual characteristics. Majority of the girls had less knowledge on reproductive health problems including awareness on AIDS, mode of transmission, abortion, etc. Age and education level of adolescent girls were the main factors which had a significant effect on their awareness levels. Appropriate knowledge and correct attitudes during adolescence may help in promoting healthy and safe sexual life and reduce the risk of STDs and AIDS.

\section{Introduction}

Adolescents form a sizeable proportion of the population, that is, around one-fifth of the total population. As per the National Family Health Survey-4 approximately 22 percent of India's population consists of adolescents in the age group of 15 to 19 years (NFHS 4, 2015-16). According to the World Health Organization (WHO, 1977) the adolescent group consists of people between the ages of 10 to 19 years. The main physical changes during this period include the adolescent's growth spurt, gonadal growth, growth of secondary sexual organs and characteristics, changes in body composition and growth of respiratory, circulatory and muscular systems. During this period, various psychological developments take place in the form of a search for identity, independence, developing a body image, sex roles, value systems and other positive values of self-reliance. These are generally coupled with the absence of scientific and authentic information to know and understand those factors which causes anxiety among the adolescents who may thus be pushed into different courses of actions without having a chance to think fully of the consequences. The adolescent girls form negative attitudes about aspects related to 
growing up, especially of menstruation and thus it affects on acceptance of these changes in their lives (Manhas and Asmat, 2014).

The National Population Policy (2000) has recognized adolescents as an undeserved vulnerable group that need to be served especially by providing reproductive health information and services. According to the World Health Organization, reproductive health refers to "a state of complete physical, mental and social well-being of and not merely the absence of disease or infirmity in all matters related to the reproductive system and its function and process.

Adolescents are an important resource of any country and on their way to adulthood they may face troubles sue to lack of right kind of information regarding their own physical and/or sexual development. Many research studies have revealed that adolescent girls generally lack adequate knowledge about sexual matters and contraception which results in early pregnancy, increased pre-marital sexual activity, increased risk of sexually transmitted infections including HIV/AIDS, maternal morbidity and mortality and unsafe abortions (Mahajan and Sharma 2004; Verma et al., 2011 and Das et al., 2016). A baseline survey by Population Council (2005) in Allahabad conducted among adolescents revealed substantial gender differences with respect to reproductive health knowledge. Lack of awareness and high prevalence of morbidity related to reproductive and genital health problems of women was also observed in Gujarat (Patel and Yadav, 2006).

Inspite of the changing social and cultural norms and practices in the society, the girls and women especially in the tribal setting have less access to health care facilities. As a result, they are ignorant of different health issues regarding their own body. In general, adolescents learn about reproductive health and sexual matters by observing the behaviour of the adults around them, by listening to peers and older siblings and through the media in all forms. Such information is often limited, wrong and confusing. This makes the adolescents especially young girls to have incorrect notions and ideas and hence may lead to unsafe health practices in future. In order to lead a healthy, responsible and fulfilling lives and protect themselves from reproductive health problems, youngsters ned to be knowledgeable about themselves and need adequate information about the various changes that take place during puberty, menstruation and other phases of life. Keeping the above things in mind, a study was planned and conducted in Meghalaya to assess the knowledge and awareness levels of adolescent girls about reproductive health.

\section{Materials and Methods}

This was cross-sectional study carried out in one of the blocks of South-West Garo Hills district of Meghalaya. A total sample of 100 adolescent school going girls of age 13 to 18 years were selected randomly from five government schools in five villages of the district. The data was collected with the help of a self-structured and pre-tested interview schedule which consisted of general information on the socio-economic background and specific questions pertaining to awareness regarding reproductive health and related practices. Permission was taken from the principals of the respective schools to conduct the interviews with the sample subjects. The girls were interviewed in the schools itself to obtain the required information. Frequencies and percentages were used for the background information and reproductive health awareness of the respondents. The data was analyzed through the use of SPSS (version 17.0). Chi-square test and correlation were also used to see the association and relation among the variables. 


\section{Results and Discussion}

\section{Socio-demographic profile}

The socio-demographic profile of the study subjects revealed that 35 per cent of the girls were in the age range of 15 to 17 years with a mean age of 16.65 years. Most of them (36\%) were in $10^{\text {th }}$ standard followed by 33 per cent in $9^{\text {th }}$ and 31 per cent in $8^{\text {th }}$ standard. It can be seen from the Table 1 that $30 \%$ of the girls had ordinal position of four and above in their families. The size of their families in majority of the cases $(71 \%)$ was medium, that is, having five to eight members which indicate that the respondents were having big families (Table 1).

\section{Knowledge regarding body changes during adolescence}

The mean age at menarche was found to be 12.67 years with a range from 12 to 15 years. All the girls had one or the other problems related to their menstrual cycle. Figure 1 presents a picture of problems faced by girls during menstruation and it was found that pain in lower abdomen (92\%) was the common problem faced by them followed by backache $(89 \%)$, weakness $(86 \%)$ and bodyache $(54 \%)$. Most of the girls seemed to be aware of the changes taking place in the body during the period of adolescence. Majority of them were aware of changes like enlargement of breasts $(41 \%)$, menstruation $(30 \%)$ and being more attractive (38\%) in girls and increase in height $(46 \%)$ and change in voice $(33 \%)$ for boys (Table 2).

Respondents were not aware of the changes in the reproductive system or the primary sexual characteristics during adolescence in boys and girls. Results also revealed a significant association between the awareness of reproductive changes with the age of respondents (Table 3).

\section{Awareness of reproductive health aspects}

All respondents were aware of some or the other reproductive health problem. Backache was known to $96 \%$ of the respondents followed by abdominal pain (94\%), urinary tract infection (47\%) and white discharge $(33 \%)$ (Table 4). It was seen that the knowledge of HIV/AIDS was very less among the girls $(36 \%)$ while only $45 \%$ could answer correctly the cause of HIV. The respondents were quite aware of the mode of transmission as the answers varied from sexual contact with infected person (36\%), infected mother to child (22\%) and through syringes and blood $(16 \%)$.

Majority of the respondents knew about abortion but didn't know about the reasons of having abortion. A significant association between the age of respondents and awareness regarding reproductive health aspects was observed (13.65 at one percent level of significance). Education level of respondents also had a significant association with the level of reproductive health awareness (Table $5)$.

Reproductive health is an important emerging issue among adolescents and especially for young girls as they represent our collective and demographic feature. Girls in their adolescent years are often ignorant about various aspects that would be helpful to them in their future. This was revealed in the present study where it was seen that awareness was lacking in adolescent girls regarding important aspects of reproductive health.

The mean age at menarche was found to be 12.67 years which is in conformity with results of various studies by Bhan et al., (2004), Singh et al., (2006), Juyal et al., (2012) and Ray et al., (2011) which reported the age at first menstruation to be between the range of 12.8 to 13.1 years. 
Table.1 Socio-demographic profile of respondents

\begin{tabular}{|c|c|c|}
\hline Sl. No. & Variables & $\begin{array}{c}\text { Percentage }(\mathrm{N}= \\
100)\end{array}$ \\
\hline \multirow[t]{4}{*}{1.} & \multicolumn{2}{|l|}{ Age (in years) } \\
\hline & $13-15$ & 24.0 \\
\hline & $15-17$ & 41.0 \\
\hline & Above 17 & 35.0 \\
\hline \multirow[t]{4}{*}{2.} & \multicolumn{2}{|l|}{ Level of education } \\
\hline & $8^{\text {th }}$ standard & 31.0 \\
\hline & $9^{\text {th }}$ standard & 33.0 \\
\hline & $10^{\text {th }}$ standard & 36.0 \\
\hline \multirow[t]{5}{*}{3.} & \multicolumn{2}{|l|}{ Ordinal Position } \\
\hline & 1 & 27.0 \\
\hline & 2 & 22.0 \\
\hline & 3 & 20.0 \\
\hline & 4 and above & 30.0 \\
\hline \multirow[t]{4}{*}{4.} & \multicolumn{2}{|l|}{ Size of family } \\
\hline & $1-4$ members & 19.0 \\
\hline & 5-8 members & 71.0 \\
\hline & Above 8 members & 10.0 \\
\hline
\end{tabular}

Table.2 Awareness of respondents regarding changes occurring in body during adolescence

\begin{tabular}{|c|l|c|}
\hline S. No. & \multicolumn{1}{|c|}{ Variables } & Percentage $(\mathbf{N}=100)$ \\
\hline 1. & Changes in Girls & 41.0 \\
\hline & Enlargement of breasts & 38.0 \\
\hline & Being more attractive & 30.0 \\
\hline & Beginning of menstruation & 12.0 \\
\hline & Increase in height & 14.0 \\
\hline & No knowledge & \\
\hline 2. & Changes in Boys & 46.0 \\
\hline & Increase in height & 33.0 \\
\hline & Changes in voice & 21.0 \\
\hline & No knowledge & \\
\hline
\end{tabular}

Table.3 Association of awareness related to reproductive changes with age of respondents

\begin{tabular}{|l|c|c|c|c|c|}
\hline Score levels & \multicolumn{3}{|c|}{ Age of respondents (in years) } & \multirow{2}{*}{ Total } & $\begin{array}{l}\text { Chi-square } \\
\text { value }\end{array}$ \\
\hline Low (Below 12) & $12-14$ & $15-17$ & Above 17 & & \multirow{2}{*}{$10.6^{*}$} \\
\hline Medium (12-24) & 1 & 14 & 5 & 20 & 61 \\
\hline High (A bove 24) & 1 & 33 & 18 & 19 & \\
\hline Total & 12 & 6 & 12 & 100 & \\
\hline
\end{tabular}

* Significant at $5 \%$ level of significance 
Table.4 Familiarity of respondents on certain reproductive health aspects

\begin{tabular}{|c|c|c|}
\hline Sl. No. & Variables & $\begin{array}{c}\text { Percentage }(\mathrm{N}= \\
100)\end{array}$ \\
\hline 1. & \multicolumn{2}{|l|}{ Reproductive health problems } \\
\hline & Backache & 96.0 \\
\hline & Abdominal pain & 94.0 \\
\hline & Urinary tract infections & 47.0 \\
\hline & White discharge & 33.0 \\
\hline 2. & Knowledge of HIV/AIDS & 36.0 \\
\hline \multirow[t]{5}{*}{3.} & \multicolumn{2}{|l|}{ Causes of HIV/AIDS } \\
\hline & No knowledge & 32.0 \\
\hline & Virus & 45.0 \\
\hline & Bacteria & 12.0 \\
\hline & Due to syringes, blood, sexual contact & 12.0 \\
\hline \multirow[t]{5}{*}{3.} & \multicolumn{2}{|l|}{ Mode of Transmission of HIV/AIDS } \\
\hline & No knowledge & 25.0 \\
\hline & Sexual contact with infected person & 36.0 \\
\hline & Trough syringes \& blood & 16.0 \\
\hline & Infected mother to child & 22.0 \\
\hline 4. & Knowledge of abortions & 59.0 \\
\hline \multirow[t]{3}{*}{5.} & \multicolumn{2}{|l|}{ Reasons of performing abortion } \\
\hline & No knowledge & 65.0 \\
\hline & Not wanting the child & 35.0 \\
\hline
\end{tabular}

Table.5 Association between levels of reproductive health awareness with age and Education of respondents

\begin{tabular}{|c|c|c|c|c|c|}
\hline \multirow[t]{2}{*}{ Variables } & \multicolumn{3}{|c|}{ Score levels } & \multirow[t]{2}{*}{ Total } & \multirow{2}{*}{$\begin{array}{l}\text { Chi- } \\
\text { square } \\
\text { value }\end{array}$} \\
\hline & $\begin{array}{c}\text { Low } \\
\text { (Below 22) }\end{array}$ & $\begin{array}{l}\text { Medium } \\
(22-32)\end{array}$ & $\begin{array}{l}\text { High } \\
\text { (Above 32) }\end{array}$ & & \\
\hline \multicolumn{6}{|c|}{ Age of respondents (in years) } \\
\hline $12-14$ & 9 & 2 & 1 & 12 & \multirow{4}{*}{$13.65 * *$} \\
\hline $15-17$ & 18 & 22 & 13 & 53 & \\
\hline Above 17 & 9 & 10 & 16 & 35 & \\
\hline Total & 36 & 34 & 30 & 100 & \\
\hline \multicolumn{6}{|c|}{ Education of respondents } \\
\hline $8^{\text {th }}$ standard & 15 & 5 & 11 & 31 & \multirow{4}{*}{$9.57 * *$} \\
\hline $9^{\text {th }}$ standard & 9 & 10 & 9 & 27 & \\
\hline $10^{\text {th }}$ standard & 11 & 21 & 10 & 42 & \\
\hline Total & 36 & 34 & 30 & 100 & \\
\hline
\end{tabular}

** Significant at $1 \%$ level of significance 
Adolescent girls, in today's world, should know about the changes taking place in their bodies and the reasons for it. It came through the present study that girls had awareness regarding some changes occurring to them during puberty, mostly the secondary sexual characteristics. They were quite unaware of the developments in primary sexual characteristics of their bodies. None of the respondents could respond to the development occurring in the reproductive system of girls. Studies done by Malleshappa et al., (2011) and Kusuma and Ahmed (2016) support the findings and stress that growing adolescents have less knowledge about their own bodies.

Another interesting thing which came through the study was the association of the awareness levels and the age of sample girls. Thus respondents who were more in age were having more knowledge on the aspect of awareness of reproductive health aspects. The results are being supported by a study done by Thabah and Ahmed (2008) on assessment of the knowledge content of adolescents on reproductive health and found that female adolescents in Meghalaya had average knowledge on puberty, sexual diseases, family planning, followed by menstruation. Their findings suggested that higher the age group, greater was the exposure to information on reproductive health and thus better knowledge.

Adolescence is a crucial decade which is marked with physical, emotional and psychological developments. With regard to the knowledge of reproductive health aspects, the present study observed that the adolescent girls seemed to have less or partial knowledge about reproductive health problems. In addition to this, they also had less awareness on HIV/AIDS, although they had some information on mode of transmission of AIDS. Inspite of the media interventions on HIV/AIDS it was surprised to observe that girls were not aware of the basic facts of AIDS. The findings are supported by the research on adolescent girls which revealed that girls lacked complete knowledge and awareness on vital life processes and several other aspects of reproductive health (Panda and Sehgal, 2009; Malleshappa et al., 2011; Pradhan, 2016 and Das et al., 2016). The age and education level of the respondents had a significant impact on their knowledge levels. This meant that the higher age group girls and with better education were more informed and had better knowledge on the aspects of reproductive health.

The present research attempted to envisage the knowledge of the young generation on aspects of reproductive health and it can be seen that awareness was lacking clearly in adolescent girls regarding important aspects of reproductive health, bodily changes during adolescence and HIV/AIDS. Today's adolescents are the adults of tomorrow. They should not only be empowered to step into the adult responsibilities and duties but also have the right for a supportive environment and opportunity to strengthen their capabilities.

\section{Recommendations}

Appropriate knowledge and correct attitudes during adolescence may help in promoting healthy and safe sexual life and thus may reduce the risk of STDs and AIDS and other related diseases. Knowledge about reproductive health and its practical implementation play a very important role in healthy development of adolescent girls, reduction of maternal morbidity, mortality and child survival. It is recommended that this knowledge can be imparted to this vulnerable group by involving various governmental and non-governmental agencies, parents, forms of media and most important the school teachers who can actually mould the lives of these young population. 


\section{Acknowledgement}

The authors wish to acknowledge the financial support and assistance provided by the Indian Council of Medical Research (ICMR), New Delhi for pursuing this research study.

\section{References}

Bhan NB, Mahajan P, and Sondhi M. 2004. Awareness regarding sexual knowledge among adolescent girls (16-20 years). The Anthropologist, 6(2):101-103.

Das, BR Nath, A.H. G. Tamoli, P. and Kakoti, G. 2016. Knowledge, attitude and practices regarding HIV/AIDS amongst the adolescents - A Hospital based study. International Journal of Health Sciences and Research, 6(1): 17.

Gupta, N. Mathur, A.K. Singh, M.P. and Saxena, N.C., 2004. Reproductive health awareness of school going unmarried adolescents. Indian Journal of Pediatrics, 71: 797-801.

Juyal, R Kandpal, SD Semwal, J and Negi, KS 2012. Practices of menstrual hygiene among adolescent girls in a district of Uttarakhand. Indian Journal of Community Health, 24(2): 124-128

Kusuma, M.L. and Ahmed, M. 2016. Awareness, perception and practices of government pre-university adolescent girls regarding menstruation in Mysore city, India. International Journal of Community Medicine and Public Health, 3(6): 1593 - 1599.

Mahajan, P and Sharma, N. 2004. Perceived Parental Relationships and the Awareness Level of Adolescents regarding Menarche. Journal of Human Ecology, 16(3): 215-216.

Malleshappa, K. Krishna, S. and Nandini, C. 2011. Knowledge and attitude about reproductive health among rural adolescent girls in Kuppam Mandal: An intervention study. Biomedical Research, 22(3): 305-310.

Manhas, S. and Asmat, S. 2014. Attitude of female adolescents of Purig Tribe towards menstruation. Asian Journal of Home Science, 9(2): 614 - 622

National Family Health Survey (NFHS-4). 2015-16International Institute of Population Sciences and ORC Macro: Mumbai. Available from: http://www.nfhsindia.org. (Retrieved on 12 September 2017)

National Population Policy. 2000. Report on National Population Policy, Department of Health and Family Welfare, Ministry of Health and Family Welfare, Government of India: New Delhi

Panda A, and Sehgal A. 2009. Impact of Information, Education and Communication on Adolescent Reproductive Health: A Sociological study of Mandi District of Himachal Pradesh. Journal of Health Management, 11(3):445-472.

Patel UA and Yadav S. 2006. Reproductive and General health Problems among women in the Reproductive age group in Jamnagar. Health and Population Perspectives and Issues, 29(4): 212223.

Population Council. 2005. India: Livelihood Skills and opportunities for Girls in Allahabad. Available from http://www.popcouncil.org/projects.

(Retrieved on 12 October 2016)

Pradhan, T. 2016. Knowledge on reproductive health issues among adolescent girls of Burla town, Sambhalpur, Odisha. International Journal of Scientific and Research Publications, 6(7):226-229.

Ray, S Ghosh, T Mondal, PC Basak, S Alauddin, $\mathrm{M}$ Chaoudhary, SM and Bisai, S. 2011. Knowledge and information on psychological, physiological and gynaecological 
problems among adolescent school girls in Eastern India. Ethiopian Journal of Health Sciences, 21(3): 183-189

Singh J, Singh JV, Srivastava AK and Suryakant. 2006. Health Status of Adolescent Girls in Slums of Lucknow. Indian Journal of Community Medicine, 31(2):102-103
Thabah V and Ahmed J. 2008. Knowledge content of adolescents on reproductive health in Shillong, Meghalaya. Asian Journal of Home Science, 3(2): 167170.

World Health Organisation.1977. Report on Health Needs of Adolescents. Technical Report Series 609, Geneva.

\section{How to cite this article:}

Shipra Nagar and Namita Singh. 2018. Assessment of Knowledge of Tribal Adolescent Girls Regarding Reproductive Health in Meghalaya, India. Int.J.Curr.Microbiol.App.Sci. 7(09): 2777-2784. doi: https://doi.org/10.20546/ijcmas.2018.709.344 